\title{
The post-2015 Global Agenda - a role for local government
}

\section{Lucy Slack}

Deputy Secretary General

Commonwealth Journal of Local Governance

London

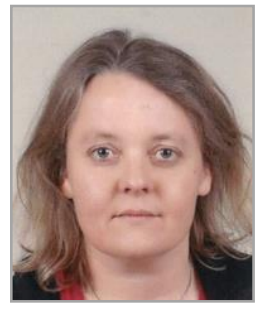

\begin{abstract}
:
As the period of implementation for the Millennium Development Goals (MDGs) draws to a close, the global community is actively debating what should replace them. Local government is working hard to ensure that the post-2015 global development agenda reflects the important role of local government in implementing the new targets. It is a unique opportunity for local government to make its voice heard, to promote the importance of localisation of the new targets, and to position local government as a key partner in the implementation of the new Sustainable Development Goals (SDGs)
\end{abstract}

Key Words: Local Government, post-2015 development agenda, Sustainable Development Goals,

In 2000 governments took an historic decision in agreeing eight targets to drive the global fight against poverty - the Millennium Development Goals (MDGs). The goals were simple and clear, ranging from eradicating extreme poverty and hunger and achieving universal primary education, to ensuring environmental sustainability and developing a global partnership for development, and they were accompanied by specific targets with a set of global indicators. At the time the Goals were developed there was little discussion around how they should be implemented and certainly few discussions around the role of local government in their delivery. 
By 2010 it was clear that progress towards meeting the goals was uneven, and some of this was as a direct result of them being seen as a top-down exercise directed by national governments, when many of the component services essential to meeting the targets, such as water provision, sanitation and primary health care are either services shared between national and local governments, or indeed the responsibility of subnational/local governments and other local stakeholders. The 2010 UN Global Forum in Uganda highlighted this, by stressing the importance of intergovernmental partnerships in meeting the targets, and the concept of localisation of global targets was born.

As the MDG period comes to an end in 2015, global focus has now turned to assessing what has been achieved, and the significant challenges countries still face in tackling poverty and reducing inequality. Substantial progress has been made - since 2000 the proportion of people living in poverty has been halved, over two billion people have gained access to improved sources of drinking water and huge gains have been made in fighting communicable diseases such as tuberculosis and malaria however the gains are uneven; at the same time, 1.2billion people globally still live in poverty, more than 2.5 billion people lack improved sanitation facilities and progress is slow in improving maternal mortality rates ${ }^{1}$.

The global debate on the post-2015 development agenda is now well underway. Unlike in 2000 when it was essentially the preserve of governments; local government, civil society, the private sector and other national, regional and international stakeholders have been far more effective in mobilising and engaging in the process. Starting with the High Level Panel set up to provide guidance to Ban Ki Moon, Secretary General of the UN, which included the Mayor of Istanbul, on behalf of local government, many rounds of formal and informal consultations and discussions have been undertaken. This has been followed by a process of more focused open working groups, there are currently (as of 2 June 2014) 17 draft Sustainable Development Goals (SDGs) on the table ${ }^{2}$.

Local government has been actively engaged throughout the process, including through the Global Taskforce of Local Regional Governments for Post-2015 and Habitat III, which brings together global organisations and networks of local government such as United Cities and Local Governments and the Commonwealth Local Government Forum, together with development partners such as UNDP to highlight and promote local government's role in the post-2015 global development agenda and beyond to Habitat III in 2016. Local government is making a strong case for its role as an implementing partner of the SDGs to be fully recognised, to ensure that targets can be set, delivered, and monitored locally. Not only are many of the key services essential to meeting the proposed SDGs delivered at the local level, but local councils are in the best position to ensure that the needs of local people are understood and met, and that the SDGs "leave no one behind".

\footnotetext{
${ }^{1}$ The data on progress towards achieving the MGDs can be accessed through www.un.org/millenniumgoals

${ }^{2}$ Zero draft of SDGs from the UN sustainable development knowledge platform

http://sustainabledevelopment.un.org/focussdgs.html
} 
The local government community has also worked with a range of other partners to highlight the impact of rapid urbanisation on development and to call specifically for a goal which focuses on the need for inclusive, safe and sustainable cities and human settlements. Cities are widely recognised to be engines of growth critical to development, but at the same time they are home to widespread poverty and face huge governance, service delivery and infrastructure challenges. Their rapid growth also impacts significantly on human settlements in rural and peri-urban areas. An "urban goal" reflecting this challenge for all human settlements is currently one of the draft SDGs reflecting the increasing emphasis globally on the impact of rapid urbanisation on the lives of the poor and disadvantaged.

The debate on localising the SDGs is gathering momentum as part of the future strategy for implementation. The United Nations has initiated a further consultation process specifically on localising the sustainable development goals (SDGs). It will be one of six further consultation exercises which will focus on how to ensure the effective implementation of the future SDGs:

1) Localisation of the SDGs

2) Helping to strengthen capacities and institutions,

3) Participatory monitoring for accountability,

4) Partnerships with civil society and other actors,

5) Partnerships with the private sector, and

6) Culture and development

The aim of the consultation is to consider what it means to localise the post-2015 agenda, particularly in terms of implementation, ie the need to understand how localisation would work - identify where the challenges will be and to start to identify concrete mechanisms, tools, innovations, and processes to translate the agenda into practice at the local level.

The consultations will bring together a cross section of local stakeholders and will seek to better understand the vision of local actors.

This will include gathering information, practical case studies of good practice, and views on the following key areas:

- Identifying the local stakeholders who will be responsible for implementing the post-2015 framework

- Analysing and defining the role and function of local governments and other stakeholders in implementing the targets

- Defining mechanisms and processes to facilitate the implementation process

- Identifying capacity gaps of local stakeholders 
- Analysing participation and inclusiveness for the implementation process including local accountability mechanisms

- Identification of simple monitoring and reporting systems including identifying data sources and gaps

- The principles of development cooperation effectiveness at the local level

- Linking the process-related discussions to the thematic areas agreed by the Open Working Group

- Territorial solidarity and the impact of rural-urban solidarity in sustainability

- The consequences of increasing urbanisation on sustainability

The consultation process presents a huge opportunity for local government and advocates of decentralisation and local development to add their support to the debate on the post-2015 development agenda through the localisation campaign but also through many of the other thematic consultations. A strong local government voice will be essential if local government's place as part of the implementation framework for the SDGs is to be secured.

There will be national consultations in 14 selected countries (Armenia, Botswana, Burundi, Cameroon, Ecuador, El Salvador, Ghana, Jamaica, Malawi, Philippines, Tajikistan, Tanzania, Uruguay and Yemen). The national consultations will be coordinated by UN Country Teams (UNCTs). Running alongside the country level consultations the process will also take advantage of relevant regional and global events, including a number of CLGF and UCLG meetings.

The CLGF Board participated in a consultation during their recent meeting in Abuja, Nigeria 12 June 2014 and members of UCLG's Executive Council held a similar event a week later in Liverpool, UK. It is clear from the recommendations of each of these events that there is a strong commitment to localisation of the SDGs. This is part of a bigger debate about the role of local government in development; the Busan Partnership for Effective Development, 2011 recognised local government as a partner in development, and the European Commission's Communication on Empowering Local Authorities in partner countries for enhanced governance and more effective development outcomes, emphasises local government's role and seeks to strengthen it to address global development challenges.

Against this backdrop, participants in the consultations emphasised the need for effective implementation of decentralisation and the importance of strengthening intergovernmental relations if localisation is to be effective. Local government associations have an important role to play in this process. The challenges of financing the localisation of the SDGs was stressed, both via providing local government with more own-source revenue streams, but also through effective decentralisation of an equitable share of existing national resources, as well as development aid support to local government, to implement the SDGs. The CLGF Board proposed the establishment of a global fund to implement the SDGs. It is clear that genuine partnerships between spheres of government - with sectoral ministries, the private sector and civil society among others - will be essential for planning, delivering and monitoring the SDGs at local level. Particular emphasis was given to the need for partnerships with the private sector in view of local government's increasing role in local economic development. 
Localisation will not be without its challenges - there will be a need to access and collect more local data to effectively measure progress at the local level, communities will need to be sensitised to the SDGs and how they affect them locally, in some countries there is a lack of political will to decentralise, and there remain many capacity gaps at the local level. However the principle of focusing on a bottom-up approach will ensure that the delivery of the SDGs is grounded in local realities, which will make a significant contribution to enabling the global community to meet the new targets.

The global debate on post-2015 is a unique opportunity for local government. However it requires action now. In addition to the national consultations and regional/global events there is provision for anyone to participate in an on-line dialogue hosted on the UN's World We Want 2015 website (www.worldwewant2015.org/localising2015). It takes a few minutes to register on the site but it ensures the opportunity to participate fully in the dialogue, and to strengthen the voice of local government in the consultation. The report, which goes to the UN for their final discussions to agree the SDGs in September at the General Assembly, will report on the national, regional and global consultations, and it will also reflect the recommendations made in the on-line dialogue.

\section{A new global settlement}

There is a real chance that localisation of the SDGs will be part of the strategy for implementing the new development agenda post 2015. If the campaign is successful it will signal an important shift in recognition of the benefits of a local approach to development and the value of building sustainable development achievements from the bottom-up as well as the top-down. Now is the time to act, to participate actively in the debate to ensure that local government's role in implementing the SDGs is recognised, and to position local government in its rightful place as one of the key partners in poverty reduction and achieving sustainable development in the post-2015 period. 